\title{
A EDUCAÇÃO NA CONCEPÇÃO DE HERBERT MARSHALL MCLUHAN (1911-1980) ${ }^{1}$
}

\author{
William Robson Cazavechia ${ }^{2}$ \\ Cézar de Alencar Arnaut de Toledo ${ }^{3}$
}

\begin{abstract}
Resumo
Análise do pensamento do intelectual Herbert Marshall McLuhan (1911-1980). Especificamente sobre a educação, entendida como processo de direcionamento moral e cultural em consonância com os interesses de grupos hegemônicos, nos Estados Unidos, entre as décadas de 1950 e 1960. A análise foi desenvolvida a partir de um aparato crítico conceitual do pensamento marxiano e envolve autores das diversas áreas do conhecimento. Tal exigência se apresenta como própria de uma abordagem abrangente quanto aos procedimentos da pesquisa bibliográfica em História da Educação. McLuhan foi um intelectual. A partir dessa categoria de análise gramsciana, compreendemos o autor canadense em suas relações sociais, na sociedade capitalista. O objetivo da análise de suas obras, principalmente aquelas escritas e publicadas entre os anos de 1954 e 1964, foi, sobretudo, o esclarecimento do vínculo que estabelece entre educação e comunicação. Seu pensamento se construiu a partir de uma noção evolutiva da história na qual a evolução das letras aos circuitos elétricos das tecnologias de informação, desenvolvidas em sua época, corresponde à evolução humana. Essa é a tese central de sua obra primordial, A Galáxia de Gutenberg (1962). Desenvolvida e continuada em seguida, no livro, Os Meios de Comunicação como Extensões do Homem (1964). A questão sobre formação humana, mediada pelas mídias, foi o modo pelo qual McLuhan procurou elucidar a questão da educação para o seu tempo.
\end{abstract}

Palavras-chave: Educação. Intelectuais. Comunicação. Século XX. Herbert Marshall McLuhan.

\section{THE EDUCATION IN THE HERBERT MARSHALL MCLUHAN'S (1911-1980) CONCEPTION}

\begin{abstract}
Analysis of the intellectual Herbert Marshall McLuhan's (1911-1980) thinking. Specifically on education, understood as a process of moral and cultural direction in line with the interests of hegemonic groups in the United States, between the 1950s and 1960s. The analysis developed from a critical conceptual apparatus of marxian's thought and involves authors of the various areas of knowledge. This requirement presents itself as a comprehensive approach to the procedures of bibliographic research in History of Education. McLuhan was an intellectual. From this category Gramscian of analysis, we understand the Canadian author in his social relations in capitalist society. The purpose of the analysis of his works, especially those written and published between years 1954 and
\end{abstract}


1964, is, above all, the clarification of the bond between education and communication. His thinking constructed from an evolutionary notion of history, in which the evolution of letters to the electrical circuits of information technologies, developed in his time, corresponds to human evolution. This is the central thesis of his early work, The Gutenberg's Galaxy (1962). Developed and continued in the book, Understanding Media (1964). The media-mediated issue of human training was one of the ways in which McLuhan sought to elucidate the question of education for his time.

Keywords: Education. Intellectuals. Communication. 20th century. Herbert Marshall McLuhan.

\section{LA EDUCACION EN LA CONCEPCIÓN DE HERBERT MARSHALL McLUHAN (1911-1980)}

\section{Resumen}

Análisis del pensamiento del intelectual Herbert Marshall McLuhan (1911-1980). En particular, sobre la educación, entendida como proceso de dirección moral y cultural en consonancia con los intereses de grupos hegemónicos, en los Estados Unidos, entre las décadas de 1950 y 1960. El análisis fue desarrollado desde un aparato crítico conceptual del pensamiento marxiano e involucra los autores de las diversas áreas del conocimiento. Tal exigencia se presenta como propia de un abordaje integral en cuanto a los procedimientos de la investigación bibliográfica en Historia de la Educación. McLuhan fue un intelectual. A partir de esa categoría de análisis gramsciana, comprendemos al autor canadiense en sus relaciones sociales en la sociedad capitalista. El objetivo del análisis de sus obras, principalmente aquellas escritas y publicadas entre los años 1954 y 1964, es, sobre todo, el esclarecimiento del vínculo que establece entre educación y comunicación. Su pensamiento se construyó a partir de una noción evolutiva de la historia, en la cual la evolución de las letras a los circuitos eléctricos de las tecnologías de información, desarrolladas en su época, corresponde a la evolución humana. Esta es la tesis central de su obra primordial, La Galaxia de Gutenberg (1962). Desarrollada y continuada a continuación, en el libro, Los Medios de Comunicación como Extensiones del Hombre (1964). La cuestión sobre la formación humana, mediada por los medios, fue uno de los modos por el cual McLuhan trató de elucidar la cuestión de la educación para su tiempo.

Palabras clave: Educación. Intelectuales. Comunicación. Siglo XX. Herbert Marshall McLuhan.

\section{INTRODUÇÃO}

A educação, na concepção do Herbert Marshall McLuhan (1911-1980), ultrapassou os limites da escola. Para ele tal necessidade adveio do fato de que o aprendizado não se limita às salas de aula. Foi uma necessidade criada pelo surgimento de um novo ambiente 
humano, quando, o que ele nomeou de Era Eletrônica e Aldeia Global, se tornaram possível. De acordo com o autor canadense, esse 'ambiente eletrônico' exigiu uma nova formulação quanto ao processo de desenvolvimento de um novo ser humano. Livre das máquinas e definida sua prática em automações, o ser humano se tornou sua própria extensão na cibernética dos meios eletrônicos de comunicação, das mídias, nos mass media. A mente humana se estendeu e o sistema nervoso humano passou a ser constituído por tecnologias eletrônicas, o que possibilitou a constituição de um ambiente eletrônico. Aliás, ele define uma correspondência direta desse ambiente eletrônico com o próprio sistema nervoso humano estendido tecnologicamente. Aí está a relação entre a educação e os media que discutimos a partir da concepção desse autor. McLuhan, enquanto intelectual, positivou a utilização dos mass media como mediadores da formação humana no momento histórico em que a produção capitalista assim o exigiu. Por isso, pensou a educação para além da sala de aula como uma forma de inclusão social das massas à essa produção.

A análise foi feita a partir de um aparato conceitual marxiano. $\mathrm{O}$ pensamento de McLuhan representou os interesses das classes dominantes na sociedade do espetáculo difuso e conciliou interesses entre elas para a formação do consenso. A sociedade capitalista, na América do Norte em meados do século XX, passou por uma transição que se deveu às novas demandas da produção. A produção mudou sua natureza. A sociedade assistiu ao espetáculo da mercadoria e se tornou a sua depositária. Ora, foi nos Estados Unidos que a sociedade do espetáculo se tornou hegemônica. Um modelo de produção aliado ao modo de vida que definiu os rumos da americanização em amplitude global. $\mathrm{O}$ American Way of life tornou-se o modo de vida na Global Village de McLuhan. E a base dessa sociedade se tornou a produção flexível do capitalismo, a produção de mercadoriasimagens a partir da extração da matéria prima da cultura, transformada em produto nas prateleiras das indústrias de distribuição. (DEBORD, 1997).

\section{FORMAÇÃO INTELECTUAL}

McLuhan foi um intelectual de origem canadense. Formou-se na academia inglesa e se radicou nos Estados Unidos da América. Em Cambridge, na Inglaterra, realizou seus estudos nas várias etapas de sua formação concomitantes ao desenvolvimento de sua concepção sobre os meios de comunicação e formação humana. Tornou-se, primeiramente, professor de literatura e mestre em língua inglesa. Deu aulas em universidades dos Estados Unidos da América e do Canadá e, quando se converteu ao catolicismo, assumiu suas atividades docentes na Universidade de Saint Louis, no Missouri, instituição de ensino superior administrada por jesuítas e na faculdade católica Saint Michael's, na Universidade de Toronto, no Canadá. (WOLFE, 2005).

Em Cambridge, desenvolveu pesquisas sobre os meios de comunicação social. Em um primeiro momento, viu neles algo de negativo, especialmente na televisão, devido aos 
conteúdos que veiculavam. Entretanto, ao conceber que o 'meio é a mensagem' assumiu uma posição positiva quanto à determinação das mídias. Escreveu uma verdadeira epopeia dos meios de comunicação. No Canadá, continuou com suas pesquisas. Sua concepção se assentou nas bases do determinismo tecnológico, de uma noção evolutiva da história e da constituição de um sistema publicitário compreendido pelo exercício da propaganda e da simulação da realidade. A educação, mediada pelos media, foi entendida por ele como entretenimento. (MCLUHAN, 2001).

McLuhan foi um intelectual e por isso é importante salientarmos que a distinção de seu papel na sociedade não está na particularidade de sua atividade ou na sua tomada de posição política. Mas no seu trabalho sob determinadas condições e relações sociais. São todos os homens intelectuais, mas nem todos exercem essa função na sociedade. (GRAMSCI, 2000). Essas funções são organizativas e conectivas, formaram-se historicamente enquanto categoria especializada para as atividades subalternas do grupo dominante.

\begin{abstract}
Os intelectuais são os "prepostos" do grupo dominante para o exercício das funções subalternas da hegemonia social e do governo político, isto é: 1) do consenso "espontâneo" dado pelas grandes massas da população à orientação impressa pelo grupo fundamental dominante à vida social, consenso que nasce "historicamente" do prestígio [...] obtido pelo grupo dominante por causa de sua posição e de sua função no mundo da produção; 2) do aparelho de coerção estatal que assegura "legalmente" a disciplina dos grupos que não "consentem", nem ativa nem passivamente, mas que é constituído para toda a sociedade na previsão dos momentos de crise no comando e na direção, nos quais desaparece o consenso espontâneo [...]. De fato, a atividade intelectual deve ser diferenciada em graus também do ponto de vista intrínseco, graus que, nos momentos de extrema oposição, dão lugar a uma autêntica diferença qualitativa: no mais alto grau, devem ser postos os criadores das várias ciências, da filosofia, da arte, etc.; no mais baixo, os mais modestos "administradores" e divulgadores da riqueza intelectual já existente, tradicional, acumulada [...]. (GRAMSCI, 2000, p. 21).
\end{abstract}

A relação que os intelectuais mantêm com o mundo da produção não é imediata, mas, mediada pelo tecido social. Estão entre a base e a superestrutura da sociedade. (GRAMSCI, 2000). A superestrutura é concebida como uma área em que as atividades culturais e ideológicas são dadas. Essa é sua noção mais simples, definida enquanto um reflexo, uma reprodução da realidade da base. Relacionada a essa noção, está uma mais substancial, pois, a própria relação é examinada. O próprio processo de mediação, processo mais amplo que as noções de reflexo e reprodução, ocorre ativa e dinamicamente. A cultura é um processo mediador e a noção de base se faz presente para sua compreensão enquanto uma atividade específica do homem. A superestrutura contém uma diversidade de atividades culturais relacionadas entre si e não pode ser compreendida apenas como um reflexo da base, como se esta última fosse uma abstração econômica e tecnológica fixas. (WILLIAMS, 2011).

Segundo Ianni (1999), na sociedade civil se encontra a possibilidade da produção de consensos emancipatórios por meio do exercício da política e de uma cultura 
revolucionária pelas classes subalternas educadas pelo partido, o moderno príncipe. Entretanto, surgiu o príncipe eletrônico no estágio do capitalismo, em meados do século $\mathrm{XX}$, quando são conciliados o lazer e o consumo, a rápida e progressiva mudança da imprensa, quando os jornais de opinião foram substituídos pelos jornais comerciais, pelo rádio e pela televisão de alcance massivo e dominados pelos financiamentos comerciais relacionados ao consumo e aos "[...] conteúdos de lazer catártico tão mais atraentes quanto fossem seus conteúdos ideologicamente alienantes.” (RAMOS, 2007, p. 37).

Com vistas a essa transformação estrutural em que a mídia exerceu, no século XX, função determinante, Ianni (1999) recorreu à metáfora do príncipe eletrônico. Se antes o intelectual estava para o moderno príncipe, o partido, em meados do século passado, ele estava para o príncipe eletrônico, os media. Com o aprimoramento tecnológico e a fabricação de novos meios de comunicação, o exercício de sua mediação se tornou central e o intelectual passou a ser, necessariamente, midiático. "Assim como as estrelas e os políticos, o intelectual existe na e pela mídia." (LECLERC, 2004, p. 88). Os intelectuais se tornaram uma espécie de representante das corporações midiáticas. Ou ainda, das corporações que delas se utilizam e mantém relações com as corporações diretamente envolvidas com esse modelo produtivo. McLuhan está entre esses intelectuais. Conciliou interesses entre as tradições católicas e a indústria da comunicação social.

Seu livro mais amplamente conhecido e que o despontou como um bem-sucedido intelectual dos meios de comunicação foi o Understanding Media: The Extensions of the Man, de 1964, publicado no Brasil em 1969 com o título de Os Meios de Comunicação como Extensões do Homem. Já havia lançado The Mecanical Bride (1951), não publicado no Brasil, e The Gutenberg Galax (1962), publicado no Brasil em 1972, com o título A Galáxia de Gutenberg, em que seu nome aparecia inteiro, Herbert Marshall McLuhan. Esse seu último livro teve uma grande procura e o tornou conhecido. A procura por seus demais textos, deveu-se ao interesse em verificar os estágios do desenvolvimento do pensamento do autor e seu estilo. Ele tomou como base toda a história da humanidade. Seus conflitos sociais, suas diferenças linguísticas, invenções técnicas, artísticas e científicas e as apresentou de modo desordenado fazendo aproximações entre acontecimentos, fatos e eras distantes a fim de evidenciar o efeito dos meios. (WOLFE, 2005).

Devemos considerar, sobretudo, que o desenvolvimento das mídias eletrônicas trouxe consigo a "[...] indústria da consciência [...]". (ENZENSBERGER, 2003, p. 11). Essa indústria se tornou, nas sociedades industriais, o controle do desenvolvimento socioeconômico. Está em todos os setores da produção e assumiu as funções de comando, de controle e determina o padrão da tecnologia dominante. Os satélites de comunicação, televisão em cores, a cabo e videocassetes, registro de imagens com tecnologia magnética, câmeras de vídeo, videofones e com estereofônico, tecnologias a lazer, fotocopiadoras, impressoras eletrônicas e impressão remota, computadores com processadores paralelos e 
banco de dados, são todas elas novas mídias. Elas se relacionam entre si e com os meios mais antigos, “[...] como a imprensa, o rádio, o cinema, a televisão, o telefone, o telex, o radar etc. Cada vez mais eles se unem em um sistema universal." (ENZENSBERGER, 2003, p. 12).

Nesse período, durante os últimos anos da década de 1940, que corresponde ao tempo de formação de McLuhan em Cambridge, ele esteve envolto por uma preocupação crítica. Uma transformação de atitudes. Adotou uma posição de estratégica. McLuhan conseguiu defender todas as suas preferências originais, apresentando-se sob o disfarce de alguém que alcançou liberdade em reação ao “[...] ponto de vista único.” (MILLER, 1973, p. 59). A correspondência é alcançada, segundo ele, roubando os produtos do conhecimento e colocando-os a trabalhar a serviço do controle deliberado. Nesse ponto, segundo a sua versão, a humanidade se viu traída por sua própria habilidade técnica. (MCLUHAN, 2001). Já se foi o tempo em que “[...] o know-how do século vinte buscava abranger o conhecimento amplo dos fins humanos e divinos. A secularização desse sistema significou a adaptação das técnicas não para fins de conhecimento, mas para propósitos de controle." (MILLER, 1973, p. 62). Tal como sempre, McLuhan se mostrou notavelmente confiante e seguro ao situar esses acontecimentos supostamente críticos na história. (MCLUHAN, 1972).

\section{MCLUHAN E OS MASS MEDIA}

Para McLuhan, a revolução do século XIX, destinava-se a substituir as leis do mercado e da economia pelas leis da natureza. Entretanto, economistas e sociólogos procuravam ainda pelas leis do mercado. O que mudou foi o que ele chamou de "evento Sputinik", que tornou o próprio planeta numa medida de natureza, que por sua vez, transformou-se em arte. "O momento do Sputinik foi a criação da nave espacial Terra e do teatro global que transformou os espectadores em atores. Hoje, portanto, todo mundo exige uma participação positiva no processo mundial." (MCLUHAN, 1972, p. 237). Para o teórico da comunicação e da publicidade, por isso, da unificação do mundo sob a rubrica de um mercado mundial inclusivo, o satélite transformou o mundo numa forma de arte.

McLuhan não criou suas proposições teóricas, mas tinham uma denominação comum de "[...] ensinamento reacionário de salvação." (ENZENSBERGER, 2003, p. 81). Embora não a tenha inventado, foi ele o primeiro a explicitar uma mística das mídias na qual problemas políticos desapareceram. O que se tornou a atração em seus textos foi a ideia da salvação da humanidade por meio da tecnologia, especialmente da televisão. Empreendimento já iniciado por vários de seus antecessores, ele dividiu a determinação de minimizar os problemas da base econômica, a partir de um enfoque idealista, sobreposto a uma banalização da luta de classes em um humanismo vago. 
Artigo

doi: $10.20396 /$ rho.v18i4.8652024

Por mais dominante e hegemônica que uma visão geral de mundo possa ser, nenhuma "[...] manipulação vinda de cima [...]" pode ser impor e transformar por completo o processo de modelagem dessa visão geral (MÉSZÁROS, 2008, p. 50). Ela é constituída por muitas concepções particulares na base de interesses hegemônicos alternativos e irreconciliáveis. Nenhum dispositivo homogêneo e uniforme pode funcionar permanentemente como promotor da lógica do capital. Não é uma natureza humana geral que determina opções e visões de mundo, mas uma contínua formação histórica e social. Por isso a necessidade de formação humana precisa considerar suas faculdades todas. "A natureza humana não é senão um dado genérico, que a história, a sociedade, o ambiente - a educação, em suma - contribuem para determinar." (MANACORDA, 2013, p. 121). A relação educativa como uma relação permanente, uma vez que uma geração educa a nova geração, e coerciva, pois a educação luta contra a natureza deve ser ampliada do plano pedagógico escolar para o das relações sociais. (MANACORDA, 2013).

As ideias do intelectual canadense surtiram efeitos ao oferecer à classe dominante dos países ricos um modo para operacionalizar os meios de comunicação com vistas à otimização da sociedade e produzir a transformação necessária para o tipo de vida que os liberais advogam para essa sociedade. Seu otimismo para com os meios de comunicação é o otimismo movido pela luta anticomunista travada pelos representantes da democracia norteamericana no período do Pós-Guerra. Mais do que o exercício da democracia política, a educação para além da escola possibilitaria, para ele, conceber a formação humana em suas dimensões conferidas pelas ciências em seus termos objetivos. Já em seus termos subjetivos, seria a própria experiência mística. Quando a arte se tornou mercadoria, sua reprodutibilidade exigiu a formação de artistas reprodutivistas. (MCLUHAN, 1973).

A formulação do professor canadense, sobre os meios de comunicação e a evolução histórica produzida por eles, foi sistematizada em uma história que retrata a evolução cultural da humanidade em três etapas: a primeira, de tribalização; a segunda, destribalização; e, a terceira, retribalização. A tribalização se iniciou com o próprio início da humanidade, quando, segundo ele, o homem adquiriu a linguagem e a incorporou como instrumento indispensável de comunicação e de sobrevivência social, quando os indivíduos deixaram simplesmente de lutar uns contra os outros e de se destruírem.

O homem foi destribalizado pelo material impresso. Passou, assim, em alguns poucos anos, de nômade primitivo a técnico alfabetizado. Num período posterior e igualmente breve, foi retribalizado pelos meios eletrônicos. $O$ resultado foi que a instrução que abandonou, o homem primitivo aceitou; a linguagem oral que ele rejeitou, o homem retribalizado aceitou. Por isso, para McLuhan foi importante a compreensão, a causa e o processo dos media. Propôs-se a desenvolver "[...] um conhecimento consciente sobre os meios impressos e as mais recentes tecnologias da comunicação e obter o máximo de cada uma no processo educacional." (CARPENTER; MCLUHAN, 1974, p. 16). Sem a 
compreensão de uma gramática dos meios de comunicação, seria impossível, segundo ele, alcançar uma consciência contemporânea do mundo em que vivia.

A terceira fase, a de retribalização, ocorreu em meados do século XX, quando a imprensa perdeu seu monopólio como meio de comunicação de massa e surgiram novos instrumentos capazes de superar fronteiras geográficas, linguísticas e culturais. A retribalização constitui uma Global Village em que a televisão se tornou o veículo básico, institucionalizou a linguagem universal, ou seja, a imagem, linguagem da evidência. (MCLUHAN, 1973; MELO, 1998). Na etapa da evolução humana de retribalização, a extensão do sistema nervoso foi produzida pela tecnologia eletrônica. Suas consequências foram proporcionalmente maiores que as anteriores, como a da invenção da roda. Por isso, faz a observação sobre o abandono escolar diante à confusão resultante da mudança súbita dos fatores ambientais. Os meios de comunicação eletrônicos produziram um ambiente eletrônico.

McLuhan dizia que a criança comum que vive nesse ambiente eletrônico, vive em mundo de sobrecarga de informação. Desde a infância ela se confronta com a imagem da televisão, com sua textura semelhante ao braile e seu caráter profundamente envolvente. Uma coisa típica da orientação retrospectiva e de hábito de encarar o novo através das lentes do velho seria o de entendermos a televisão como uma extensão das nossas faculdades visuais. Ela é, para ele, muito mais uma extensão do sentido integrador e ativo do tato. "Qualquer momento de televisão propicia mais dados do que os que poderiam ser registados em uma dúzia de páginas de prosa." (MCLUHAN, 2005, p. 83). As crianças, acostumadas a uma grande quantidade de dados em seus ambientes cotidianos, se veem diante uma contradição grave quando são introduzidas em salas de aula e currículos do século XIX, onde o fluxo de dados é pequeno. Esse choque ambiental pode anular a motivação na aprendizagem. (MCLUHAN, 2005, p. 84).

Desse modo, a proposta de McLuhan para a educação foi a criação dos ambientes para a formação do homem conforme as tecnologias entendidas como extensões de seu próprio corpo e mente. "Penso nas tecnologias como extensões de nosso próprio corpo, de nossas próprias faculdades, quer se trate das roupas, da habitação, quer se trate dos tipos mais familiares de tecnologias, como as rodas, os estribos, que são extensões de várias partes do corpo." (MCLUHAN, 2005, p. 90). Daí adveio a necessidade de ampliar as capacidades humanas de forma que possa lidar com vários ambientes. "Essas amplificações de nossas capacidades, espécies de definições do homem, eu as defino como tecnologias. Elas criam ambientes." (MCLUHAN, 2005, p. 90). Aqui se encontra um dos aspectos mais importantes de sua concepção. Toda tecnologia faz ao mesmo tempo um rearranjo de padrões de associação humana e cria um novo ambiente nem sempre notado. Qualquer meio, então, seja ele o rádio ou televisão, está predisposto a criar um novo ambiente humano (MCLUHAN, 2005). Essa pressuposição lhe permite fazer a seguinte incursão: 
Se o papel natural do sistema de circuitos é a profundidade e um envolvimento e responsabilidade crescentes, diríamos que ele não requer um grande aumento da autonomia e da consciência humanas. Acho que, se existe uma lógica, e parece haver uma lógica auspiciosa, essa lógica é a completa disseminação de todos os aspectos inconscientes de nossa vida; para vivermos com nós mesmos nessa profundidade, nessas situações de feedback instantâneo, teremos de entender tudo para que a nossa complacente acomodação ao inconsciente não possa perdurar; teremos de assumir a totalidade do ambiente humano como um artefato. (MCLUHAN, 2005, p. 108).

A utilização das artes no que elas têm de melhor, nesse sentido, seria uma forma de aumentar a percepção do ambiente. Sem ela não há consciência. Ou melhor, era preciso desenvolver a habilidade total para converter o próprio ambiente numa obra de arte, ou seja, "de percepção transcendente", essa é a lógica dessa forma. A produção de ambientes como artefatos, como obras de arte, conforme McLuhan, foi algo para o qual as pessoas caminharam juntas. Por isso cita, como exemplo, os próprios planejadores urbanos, para os quais seus intentos foram de moldar o ambiente total como um artefato ao invés de se limitarem a introduzir artefatos nos ambientes. "A necessidade de nos tornarmos inteiramente autônomos e cônscios de todas as consequências de tudo o que estamos fazendo antes que as consequências sobrevenham, eis para onde estamos indo." (MCLUHAN, 2005, p. 109).

Nos anos de 1950 e de 1960, quando o poderio tecnológico tomou conta do ambiente global a fim de manipulá-lo se fosse o material da arte. Nesse mesmo momento, a eficácia da sala de aula, em sua nova função, promoveu o declínio da cultura do livro. "Assim como Erasmo via a sala de aula como o novo palco para o drama da imprensa, verificamos hoje que a situação nova que se oferece igualmente aos jovens e velhos é a sala de aula sem paredes." (MCLUHAN, 2011, p. 168). Conforme asseverou McLuhan em seus textos, todo o ambiente urbano se tornou pedagógico, pois tudo e todos tem uma mensagem a declarar e um fio a ligar a outro. O circuito foi delineado em um arranjo global. Essa é sua aldeia global, na qual o homem retribalizado foi, na verdade, cibernetizado.

$\mathrm{Na}$ concepção do autor canadense, a automação tornou obrigatória a educação liberal. A "era elétrica" produziu os servomecanismos e liberou os homens dessa servidão mecânica e especializada de uma era anterior, maquinizada. Da mesma forma que a máquina e o automóvel liberaram o cavalo e o projetaram ao plano do entretenimento, a automação procedeu em relação aos homens e exigiu deles uma participação imaginativa na sociedade. Foi isso que permitiu a percepção das rotinas monótonas dos procedimentos mecânicos. Como a história da cultura demonstra em sua perspectiva, o homem coletor de comida teve de assumir tarefas que contavam com posições fixas e sedentárias. Por isso se especializou e, com o desenvolvimento da escrita e da imprensa, marcou uma fase importante desse processo. Entretanto, por isso mesmo, se tornaram especializados em separar “[...] os papéis do conhecimento dos papéis da ação." (MCLUHAN, 2001, p. 401). Foi com a eletricidade e a automação que a tecnologia dos processos fragmentados se 
fundiu com o próprio diálogo humano a necessidade da unidade humana considerada integralmente.

\section{CONSIDERAÇÕES FINAIS}

A questão educacional, na concepção mcluhaniana, assenta-se em uma problemática em torno do sistema educacional. Ela parte da análise de que não foi desenvolvido um sistema educacional programado para treinar a percepção do mundo exterior. A passagem para essa atividade produzirá um tipo de choque ou trauma que pode ser superado tendo em vista o público acostumado com o entretenimento, acostumado a perceber essa exterioridade. Principalmente "[...] as crianças em nosso sistema escolar atual dispõem de recursos informacionais de nível muito elevado tanto em seus próprios sistemas nervoso e constitucional como no mundo que lhes é imediatamente acessível." (MCLUHAN, 2005, p. 127). Quando chamou a atenção para esse fato, McLuhan tinha em vista a própria natureza da publicidade. Afinal, o entretenimento e a publicidade, ou o entretenimento na publicidade, compõem elementos importantes da educação no ambiente produzido pelos meios de comunicação eletrônicos.

A sua proposta sobre a educação está no interior da luta de classes. Como tal, as discussões em torno dela foram oportunas tendo em vista a tentativa de resoluções das contradições do capital, do qual a cultura do dinheiro é a sua expressão. Se cultura é trabalho, trabalha-se, na aldeia global de McLuhan, com o equivalente universal. Se educação e trabalho estão sempre relacionados, a proposta, então, da educação mediada pelos media, diz respeito à preparação dessa classe trabalhadora, que o capitalismo representa, em fragmentos sociais, para o trabalho globalizado.

\section{REFERÊNCIAS}

CARPENTER, E.; MCLUHAN, M. (Org.). Revolução na comunicação. 3. ed. Rio de Janeiro: Zahar, 1974.

DEBORD, G. A Sociedade do espetáculo. Rio de Janeiro: Contraponto, 1997.

ENZENSBERGER, H. M. Elementos para uma teoria dos meios de comunicação. São Paulo: Conrad Editora do Brasil, 2003.

GRAMSCI, A. Cadernos do cárcere. Rio de Janeiro: Civilização Brasileira, 2000. v. 2.

IANNI, O. O príncipe eletrônico. Perspectivas. São Paulo, v. 22, p. 11-29, 1999.

Disponível em: <http://seer.fclar.unesp.br/perspectivas/article/viewFile/2079/1701>.

Acesso em: 15 maio 2016. 
LECLERC, G. Sociologia dos intelectuais. São Leopoldo: Ed. da UNISINOS, 2004.

MANACORDA, M. A. O princípio educativo em Gramsci: americanismo e conformismo. 2. ed. Campinas: Alínea, 2013.

MCLUHAN, H. M. A galáxia de Gutenberg: a formação do homem tipográfico. São Paulo: Companhia Editorial Nacional, 1972.

MCLUHAN, H. M. Cibernética e cultura humana. In: MCLUHAN, S.; STAINES, D. (Org.). McLuhan por McLuhan: conferências e entrevistas. Rio de Janeiro: Ediouro, 2005. p. $75-86$.

MCLUHAN, H. M. Os meios de comunicação como extensões do homem. 14. ed. São Paulo: Cultrix, 2001.

MCLUHAN, H. M. Visão, som e fúria. In: LIMA, L. C. Teoria da cultura de massa. 8. ed. São Paulo: Paz e Terra, 2011.

MCLUHAN, H. M.; WATSON, W. Do clichê ao arquétipo. Rio de Janeiro: Record, 1973.

MELO, J. M. de. Teoria da comunicação: paradigmas Latino-Americanos. Petrópolis: Vozes, 1998.

MÉSZÁROS, I. A Educação para além do capital. 2. ed. São Paulo: Boitempo, 2008.

MILLER, J. As idéias de McLuhan. São Paulo: Cultrix; EDUSP, 1973.

RAMOS, M. C. Sobre a importância de repensar e renovar a idéia de sociedade civil. In: RAMOS, M. C.; SANTOS, S. dos. (Org.). Políticas de comunicação: buscas teóricas e práticas. São Paulo: Paulus, 2007.

WILLIAMS, R. Cultura e materialismo. São Paulo: Ed. da UNESP, 2011.

WOLFE, T. Introdução. In: MCLUHAN, S.; STAINES, D. (Org.). McLuhan por

McLuhan: conferências e entrevistas. Rio de Janeiro: Ediouro, 2005. p. 7-24.

Notas

${ }^{1}$ O texto é parte dos resultados da pesquisa desenvolvida, em nível de mestrado, pelo Programa de Pós Graduação em Educação da Universidade Estadual de Maringá, concluída no ano de 2017. Sua apresentação final para revista HISTEDBR contou com uma reedição após as discussões suscitadas na participação no II SIPERS, na cidade de Cascavel - PR, no mesmo ano.

${ }^{2}$ Mestre em Educação (UEM, 2017); Programa de Pós Graduação em Educação da Universidade Estadual de Maringá, Maringá. Direção eletrônica: cazavechia.william @hotmail.com.

${ }^{3}$ Doutor em Educação (UNICAMP, 1996) Programa de Pós Graduação em Educação da Universidade Estadual de Maringá, Maringá. Direção eletrônica: caatoledo@uem.br. 


\section{Revista HIIS'T'EDBR (On-lime}

Submetido em: 23/03/2018

Aprovado em: 15/10/2018

Publicado em: 14/11/2018 